\title{
Design and optimization of axial flux brushless DC generator dedicated to generation of renewable energy
}

\author{
Souhir Tounsi \\ National School of Electronics and Telecommunications of Sfax, Sfax University, SETIT Research Unit, Sfax, Tunisia \\ Email address: \\ souhir.tounsi@isecs.rnu.tn
}

To cite this article:

Souhir Tounsi. Design and Optimization of Axial Flux Brushless DC Generator Dedicated to Generation of Renewable Energy. American Journal of Electrical Power and Energy Systems. Special Issue: Design and Monitoring of Renewable Energy Systems (DMRES).

Vol. 4, No. 3-1, 2015, pp. 1-5. doi: 10.11648/j.epes.s.2015040301.11

\begin{abstract}
In this paper, we present a design model of permanent magnet generator dedicated to generate renewable energy, taking in account of several systemic and physical constraints. Being couple to a model of the losses of the power chain and to a model of the mass of the generator, this analytic model puts a problem of conjoined optimization of the recovered energy and the cost of the generator. This problem is solved by genetic algorithms method.
\end{abstract}

Keywords: Renewable Energy, Design, Generator, Converters, Optimization

\section{Introduction}

A modular axial generator structure with permanent magnet reducing the cost of manufacture is chosen to generate renewable energy [1], [2], [3], [4] and [5].

We choice the analytic method to conceive the permanent magnet generator seen its compatibility to optimization approaches. Indeed, it's fast and product results quickly and without iterations.

The coupling of power chain losses model and the model of the generator mass to the program dimensioning the generator, pose an optimization problem. This last is solved by the software of optimization based on the Genetic Algorithm method.

\section{Renewable Energy System}

The system generating renewable energy comprises:

- A propeller attached to the rotor transmitting the mechanical energy caused by the movement of the air to the stator.

- A synchronous generator with permanents magnets to convert mechanical energy from the rotor in an alternating electrical energy.

- $\quad \mathrm{AC}-\mathrm{DC}$ converter to convert the alternative energy into continuous energy.

- $\quad$ DC-DC converter to elevate voltage loading batteries to optimize the recovered energy.
- $\quad$ An energy accumulator for energy storage.

\section{Structures of the Electric Generator}

\subsection{Manufacturing Cost Reduction}

The electric generator structure is modular i.e. it can be with several stages. This technology allows the reduction of the production cost of these generators types. The slots are right and open what facilitates the coils insertion and reduces the generator manufacturing cost. The concentrated winding is used because of its advantages:

- Reduction of the manufacturing time of this generator (insertion of coils in one block).

- Reduction of the end-windings.

- Reduction of the generator bulk.

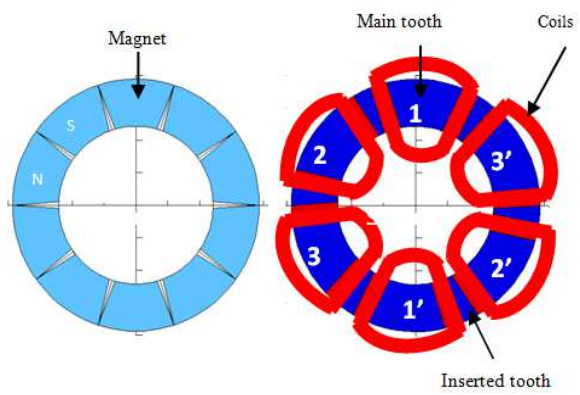

Figure 1. 5 pairs of poles, 6 main teeth, axial flux and trapezoidal configuration. 
Figure 1 illustrates the first trapezoidal configuration $(n=1)$ with axial flux only one stage [6].

Five configurations with a trapezoidal wave-form are found while being based on optimization rules of the ripple torque and cost. Each configuration is characterized by a variation law of the pole pairs number ( $p$ ) according to an integer number $n$ varying from one to infinity, the ratio $(r)$ of the number of main teeth $\left(\mathrm{N}_{\mathrm{t}}\right)$ by the number of pole pairs, the ratio $(\mathrm{v})$ between the angular width between two main teeth and that of a principal tooth, the ratio $(\alpha)$ between the angular width of a principal tooth and that of a magnet and the ratio $(\beta)$ between the angular width of a magnet and the polar step. Table .1 gives these ratios for these configurations [6], [7], [8], [9].

Table 1. Found configurations.

\begin{tabular}{llllll}
\hline Trapezoidal configurations & $\mathbf{p}$ & $\mathbf{r}$ & $\mathbf{v}$ & $\boldsymbol{\alpha}$ & $\boldsymbol{\beta}$ \\
\hline 1 & $2 . n$ & 1.5 & $1 / 3$ & 1 & 1 \\
2 & $5 . \mathrm{n}$ & 1.2 & $2 / 3$ & 1 & 1 \\
3 & $7 . \mathrm{n}$ & $6 / 7$ & $4 / 3$ & 1 & 1 \\
4 & $4 . \mathrm{n}$ & 0.75 & $5 / 3$ & 1 & 1 \\
5 & $5 . \mathrm{n}$ & 0.6 & $7 / 3$ & 1 & 1 \\
\hline
\end{tabular}

\subsection{Design Methodology}

We choose the analytic modelling of the generator, because it's compatible to the optimizations approaches [10], [11], [12], [13].

The worksheet computes the geometrical dimensions of rotor and stator as well as windings, temperature, inductance, leakages and efficiency for different operating points.

A sizing program is developed with equations detailed below. The program inputs are:

1. Generator specifications.

2. Materials properties.

3. Configuration, i.e. magnet number and teeth number.

4. Inner and outer diameter of the motor.

5. Notebook data.

6. Current density in coils $\delta$.

7. Rotor yoke $B_{r y}$, stator yoke $B_{\text {sy }}$, flux density in the air-gap $B_{g}$ and number of phase turn $\mathrm{N}_{\mathrm{s}}$.

When inputs 3 . and 4 . are set, magnet shapes, teeth and slots are fixed. Then, the area of one tooth $A_{t}$ and the average length of a spire $\mathrm{L}_{\mathrm{sp}}$ are calculated from geometric equations.

This model is validated by finite elements method. Indeed, the generator is drawn according to its geometrical magnitudes extracted from analytical model with the software Maxwell-2d, and is simulated in dynamic and static in order to compare the results obtained with those found by the analytical method.

The coupling of this model to a model evaluating the power train losses and generator mass, poses an optimization problem with several variables and constraints. This latter is solved by the genetic algorithms (GAs) method [10], [11], [12], [13].

\section{Dimensioning Torque}

The generator constant is defined by [10], [11], [12], [13]:

$$
\mathrm{K}_{\mathrm{e}}=2 \times \mathrm{N}_{\mathrm{s}} \times \mathrm{A} \times \mathrm{B} \times \mathrm{B}_{\mathrm{g}}
$$

For the axial flux structures A and B are given by:

$$
\begin{gathered}
A=\frac{D_{e}-D_{i}}{2} \\
B=\frac{D_{e}+D_{i}}{2}
\end{gathered}
$$

The dimensioning torque is given by the following relation:

$$
\mathrm{T}_{\mathrm{dim}}=\frac{1.137 \times \mathrm{r} \times \mathrm{v}_{\max }^{3}}{\Omega_{\max }}
$$

where $\mathrm{V}_{\max }$ is the maximum air velocity, $\mathrm{r}$ is the radius of the rotor and $\Omega_{\max }$ is the maximum angular speed of the generator.

The dimensioning current is expressed as follows:

$$
I_{\text {dim }}=\frac{T_{\text {dim }}}{2 \times N_{s} \times A \times B \times B_{g}}
$$

\section{Generator Sizing}

The air-gap flux density is calculated for a maximal recovery position, or the magnet is in front of a main tooth. At this position the air-gap flux density is maximal. The distribution of the field lines to the level of a pole is illustrated by the figure 2 :

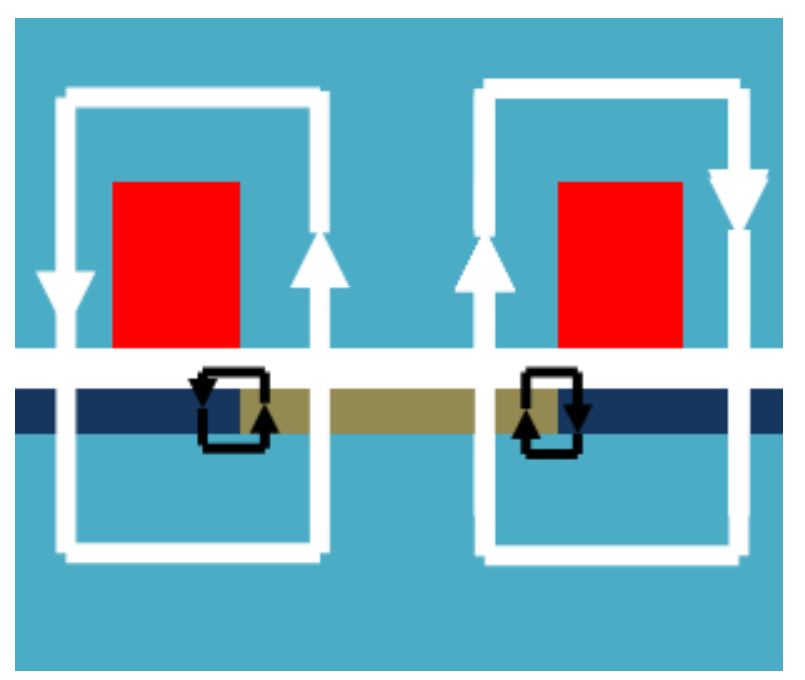

Figure 2. Flux lines distribution at maximal recovery position.

The flux decomposes itself in main flux and in leakages flux between magnets.

As applying the Ampere theorem to the level of a stator pole, we can deduct the flux density due to the stator current.

$$
\int_{\text {flux lines }} \overrightarrow{\mathrm{H}} \times \overrightarrow{\mathrm{dl}}=\frac{\mathrm{N}_{\mathrm{s}}}{2} \times \mathrm{I}_{\max }=2 \times\left(\mathrm{H}_{\mathrm{ri}} \times \mathrm{t}_{\mathrm{m}}+\mathrm{H}_{\mathrm{ri}} \times \mathrm{g}\right)
$$

where $I_{\max }$ is the stator maximal current, $H$ is the magnetic 
field, $H_{r i}$ is the air-gap magnetic field, $t_{m}$ is the magnet thickness and $\mu_{0}$ is the air permeability.

$$
\mathrm{B}_{\mathrm{ri}}=\mu_{0} \times \mathrm{H}_{\mathrm{ri}}
$$

where $\mathrm{B}_{\mathrm{ri}}$ is the flux density in the air-gap due to the stator current.

$$
\text { Bri }=\frac{\mu_{0}}{4} \times \frac{N_{s} \times I_{\max }}{t_{m}+g}
$$

While applying the Ampere theorem, we can deduct the magnet thickness imposing a fixed flux density in the different zones of the motor while disregarding the flux density due to the stator current circulation, since the flux must cross two times the air-gap thickness and magnet with permeability very close to the air permeability.

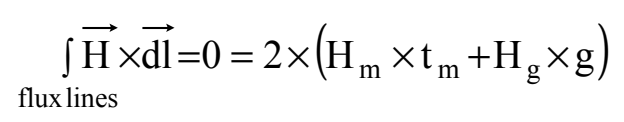

The air-gap flux density is linear according to the magnetic field for this working regime:

$$
\mathrm{B}_{\mathrm{g}}=\mu_{0} \times \mathrm{H}_{\mathrm{g}}
$$

While applying the flux conservation theorem to the level of the air-gap, we deduct the value of the air-gap flux density in function of the magnet flux density and the coefficient of the leakages flux.

$$
\mathrm{B}_{\mathrm{m}} \times \mathrm{S}_{\mathrm{m}} \times \mathrm{K}_{\mathrm{fu}}=\mathrm{B}_{\mathrm{g}} \times \mathrm{S}_{\mathrm{m}}
$$

The magnet flux density becomes:

$$
\mathrm{B}_{\mathrm{m}}=\frac{\mathrm{B}_{\mathrm{g}}}{\mathrm{K}_{\mathrm{fu}}}
$$

The magnet flux density is approached by the following linear equation:

$$
\mathrm{B}_{\mathrm{m}}=\mu_{0} \times \mu_{\mathrm{m}} \times \mathrm{H}_{\mathrm{m}}+\mathrm{B}_{\mathrm{r}}
$$

where $\mu_{\mathrm{m}}$ is the magnet's relative permeability, $B_{\mathrm{r}}$ is the remanence.

From the equation (10), (11), (12) and (13), we deduct the magnet thickness fixing the air-gap flux density equal to $\mathrm{B}_{\mathrm{g}}$ :

$$
\mathrm{t}_{\mathrm{m}}=\mu_{\mathrm{m}} \times \frac{\mathrm{B}_{\mathrm{g}}}{\mathrm{B}_{\mathrm{r}}-\frac{\mathrm{B}_{\mathrm{g}}}{\mathrm{K}_{\mathrm{fu}}}} \times \mathrm{g}
$$

where $\mathrm{K}_{\mathrm{fu}}<1$ is the magnet's leakage coefficient and $\mathrm{g}$ is the air-gap thickness. To avoid demagnetization, the phase currents must be lower then the demagnetization current $I_{d}[8]$ :

$$
I_{d}=\left(\frac{B_{r}-B_{\text {min }}}{\mu_{m}} \times t_{m}-B_{\text {min }} \times K_{f u} \times g\right) \times \frac{p}{2 \times \mu_{0} \times N_{s}}
$$

where Bmin is the minimum flux density allowed in the magnets and $\mu 0$ is the air permeability. The rotor yoke thickness try and stator yoke thickness tsy derive from the flux conservation [9]:

$$
\begin{gathered}
t_{r y}=\frac{B_{g}}{B_{r y}} \times \frac{\operatorname{Min}\left(A_{t}, A_{m}\right)}{2 \times A} \times \frac{1}{K_{f u}} \\
t_{s y}=\frac{B_{g}}{B_{s y}} \times \frac{\operatorname{Min}\left(A_{t}, A_{m}\right)}{2 \times A}
\end{gathered}
$$

where $A_{t}$ is the tooth area, $A_{m}$ is the area of one magnet, $B_{r y}$ and $\mathrm{B}_{\mathrm{sy}}$ are respectively the flux densities in rotor and stator yokes. For the axial flux and trapezoidal wave-form motor configurations the slot height is [9]:

$$
\mathrm{h}_{\mathrm{s}}=\frac{3 \cdot 2 \cdot \mathrm{N}_{\mathrm{s}}}{2 \mathrm{~N}_{\mathrm{t}}} \frac{\mathrm{I}_{\mathrm{dim}}}{\delta} \frac{1}{\mathrm{~K}_{\mathrm{f}}} \frac{1}{\mathrm{~A}_{\mathrm{s}}}
$$

where $\mathrm{N}_{\mathrm{t}}$ is the number of principal teeth, $\delta$ is the current density in slots, $\mathrm{K}_{\mathrm{f}}$ is the slot filling factor, $\mathrm{A}_{\mathrm{s}}$ is the slot width and $\mathrm{I}_{\mathrm{dim}}$ is the dimensioning current:

$$
\mathrm{I}_{\mathrm{dim}}=\frac{\mathrm{T}_{\mathrm{dim}}}{\mathrm{K}_{\mathrm{e}}}
$$

The slot width is expressed as follows:

$$
A_{s}=B \times \operatorname{SIN}\left(\frac{1}{2} \times\left(\frac{2 \times \pi}{N_{t}}-\alpha \times \beta \times \frac{\pi}{p} \times\left(1-r_{\text {did }}\right)\right)\right)
$$

where $r_{\text {did }}$ is the ratio between the angular width of the inserted tooth and that of the principal tooth. This ratio is optimized by finite elements simulations in order to reduce the flux leakages and to improve the electromotive force wave-form.

\section{Optimization Problem}

The optimization problem consists on the determination of the generator sizes minimizing its mass and the power train losses, while respecting the technological constraints of the application.

The generator weight is expressed as follows:

$$
\mathrm{W}_{\mathrm{m}}=\mathrm{W}_{\mathrm{sy}}+\mathrm{W}_{\mathrm{t}}+\mathrm{W}_{\mathrm{c}}+\mathrm{W}_{\mathrm{ry}}+\mathrm{W}_{\mathrm{m}}
$$

For the axial flux configurations the weight of stator yoke $\mathrm{W}_{\text {sy }}$, tooth $\mathrm{W}_{\mathrm{t}}$, copper $\mathrm{W}_{\mathrm{c}}$, rotor yoke $\mathrm{W}_{\mathrm{ry}}$, and magnets $\mathrm{W}_{\mathrm{m}}$ are expressed as follows:

$$
\begin{aligned}
& \mathrm{W}_{\mathrm{sy}}=\mathrm{n} \times \mathrm{d} \frac{\pi}{4} \times\left(\mathrm{D}_{\mathrm{e}}^{2}-\mathrm{D}_{\mathrm{i}}^{2}\right) \times \mathrm{t}_{\mathrm{sy}} \\
& \mathrm{W}_{\mathrm{t}}=\mathrm{n} \times \mathrm{d} \times \mathrm{N}_{\mathrm{t}} \times \mathrm{A}_{\mathrm{t}} \times \mathrm{h}_{\mathrm{s}} \\
& \mathrm{W}_{\mathrm{c}}=3 \times \mathrm{n} \times \mathrm{N}_{\mathrm{s}} \times \mathrm{L}_{\mathrm{sp}} \times \frac{\mathrm{I}_{\mathrm{dim}}}{\delta} \times \mathrm{d}_{\mathrm{c}}
\end{aligned}
$$




$$
\begin{gathered}
\mathrm{W}_{\mathrm{ry}}=\pi \times\left(\left(\frac{\mathrm{D}_{\mathrm{e}}}{2}\right)^{2}-\left(\frac{\mathrm{D}_{\mathrm{i}}}{2}\right)^{2}\right) \times \mathrm{t}_{\mathrm{ry}} \times \mathrm{d} \\
\mathrm{W}_{\mathrm{m}}=2 \times \mathrm{n} \times \mathrm{p} \times \mathrm{A}_{\mathrm{m}} \times \mathrm{t}_{\mathrm{m}} \times \mathrm{d}_{\mathrm{m}}
\end{gathered}
$$

where $d$ is the density of the metal sheet, $d_{c}$ is the density of copper, $d_{m}$ is the magnet density, $A_{a}$ is the magnet angular width, $A_{d}$ is the angular width of principal teeth and $A_{e}$ is the slot angular width.

For the trapezoidal wave-form configurations, the copper losses are expressed by the following relation:

$$
\mathrm{P}_{\mathrm{c}}=2 \times \mathrm{R} \times \mathrm{I}^{2}
$$

The phase resistance is given by the following expression:

$$
\mathrm{R}=\mathrm{r}_{\mathrm{cu}}\left(\mathrm{T}_{\mathrm{b}}\right) \times \frac{\mathrm{N}_{\mathrm{s}} \times \mathrm{L}_{\mathrm{sp}}}{\mathrm{S}_{\mathrm{c}}}
$$

where $r_{c u}$ is the copper receptivity, $L_{s p}$ is the average length of spire, $\mathrm{T}_{\mathrm{b}}$ is the copper temperature and $\mathrm{S}_{\mathrm{c}}$ is the active section of one conductor:

$$
\mathrm{S}_{\mathrm{c}}=\frac{\mathrm{I}_{\mathrm{dim}}}{\delta}
$$

The iron losses are expressed by the following relation [14], [15], [16], [17], [18], [19]:

$$
\mathrm{P}_{\mathrm{fer}}=\mathrm{C} \times \mathrm{f}^{1.5} \times\left(\mathrm{n} \times \mathrm{W}_{\mathrm{t}} \times \mathrm{B}_{\mathrm{g}}^{2}+\mathrm{n} \times \mathrm{W}_{\mathrm{sy}} \times \mathrm{B}_{\mathrm{sy}}^{2}\right)
$$

where $\mathrm{c}$ is the core loss, $\mathrm{f}$ is the motor supplying frequency, $\mathrm{W}_{\mathrm{t}}$ is the teeth weight, $W_{\text {sy }}$ is the stator yoke weight, $B_{g}$ is the ai-rgap flux density and $\mathrm{B}_{\mathrm{sy}}$ is the flux density in stator yoke. The mechanical losses are expressed by the following relation [11]:

$$
\mathrm{P}_{\mathrm{m}}=\left(\mathrm{T}_{\mathrm{b}}+\mathrm{T}_{\mathrm{vb}}+\mathrm{T}_{\mathrm{fr}}\right) \times \Omega
$$

where $\Omega$ is the angular speed of the electric generator.

The losses in the static converter are nearly hopeless, they are not held in account in the model of power train losses calculation.

$$
\mathrm{P}_{\mathrm{ptl}}=\mathrm{P}_{\mathrm{c}}+\mathrm{P}_{\mathrm{fer}}+\mathrm{P}_{\mathrm{m}}
$$

\section{Genetic Algorithms Optimization of the Generator Mass and the Power Train Losses}

The function to optimize is expressed by the following expression:

$$
\mathrm{F}_{\mathrm{o}}=\mathrm{W}_{\mathrm{m}}+\mathrm{a} \mathrm{P}_{\mathrm{ptl}}
$$

Where " $\mathrm{a}$ " is a coefficient fixing the influence degree of $\mathrm{P}_{\mathrm{ptl}}$ at the global objective function compared to $\mathrm{W}_{\mathrm{m}}$. Indeed, "a" brings closer the value of $\left(\mathrm{a}_{\mathrm{ptl}}\right)$ to the value of $\mathrm{W}_{\mathrm{m}}$.

The optimization problem consists in optimizing the $F_{o}$ with respect to the problem constraints. In fact, Genetic Algorithms (GAs) are used to find optimal values of the internal diameter $D_{i}$, the external diameter $D_{e}$, the flux density in the air-gap $B_{g}$, the current density in the coils $\delta$, the flux density in the rotor yoke $B_{\text {ry }}$, the flux density in the stator yoke $B_{\text {sy }}$ and the number of phase spires $\mathrm{N}_{\mathrm{s}}$ [14], [15], [16], [17], [18], [19].

The beach of variation of each parameter xi $\in \quad\left(D_{i}, D_{e}, B_{g}\right.$, $\delta, \mathrm{B}_{\mathrm{ry}}, \mathrm{B}_{\text {sy }}, \mathrm{Ns}$ ) must respect the following constraint: $\mathrm{x}_{\text {imin }}$ $\leq \mathrm{x}_{\mathrm{i}} \leq \mathrm{x}_{\text {imax }}$. The values of the lower limit $\mathrm{x}_{\text {imin }}$ and the upper limit $x_{i m a x}$ are established following technological, physical and expert considerations.

The $\mathrm{F}_{\mathrm{o}}$ model is coupled to a program of optimization by the method of the genetic algorithm. The progress of the program of optimization of the $\mathrm{F}_{\mathrm{o}}$ with constraints is described by this organization diagram (figure 3) [14], [15], [16], [17], [18]:

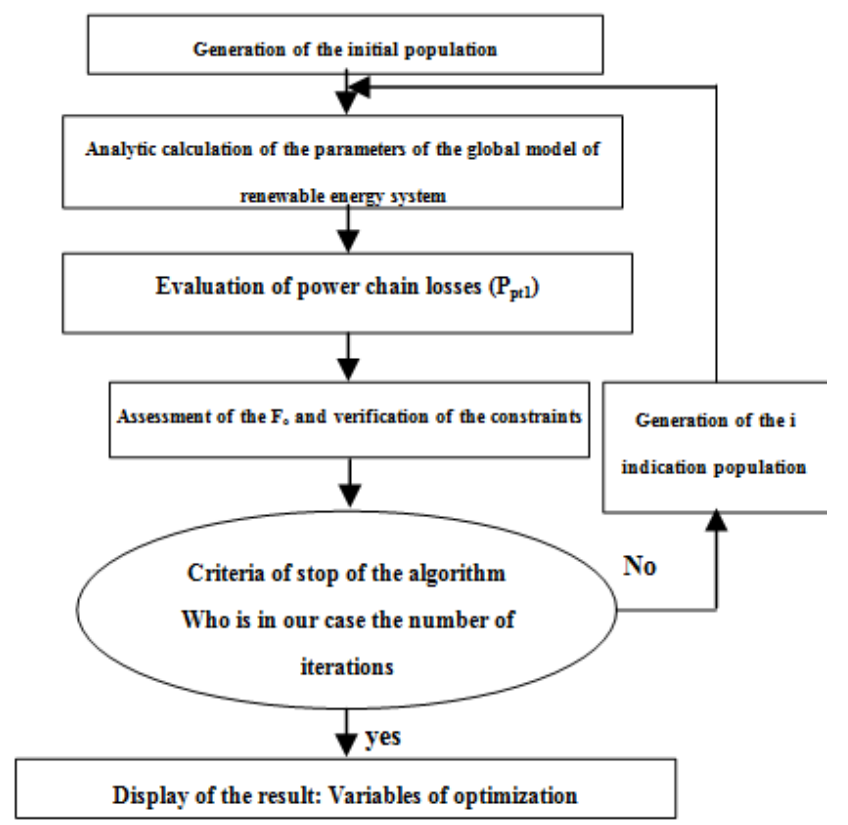

Figure 3. Progress of the optimization program.

\section{Conclusion}

An analytical model dimensioning the renewable energy generator is developed. This model is coupled to an optimization program in order to find the design prameters of the generator minimizing the power train energy losses and the generator cost. This study encourages the manufacture procedure the studied generator [9], [14], [15], [16], [17], [18], [19].

\section{References}

[1] Chaithongsuk, S., Nahid-Mobarakeh, B., Caron, J., Takorabet, N., \& Meibody-Tabar, F. : Optimal design of permanent magnet motors to improve field-weakening performances in variable speed drives. Industrial Electronics, IEEE Transactions on, vol 59 no 6, p. 2484-2494, 2012. 
[2] Rahman, M. A., Osheiba, A. M., Kurihara, K., Jabbar, M. A., Ping, H. W., Wang, K., \& Zubayer, H. M. : Advances on single-phase line-start high efficiency interior permanent magnet motors. Industrial Electronics, IEEE Transactions on, vol 59 no 3, p. 1333-1345, 2012.

[3] C.C Hwang, J.J. Chang : Design and analysis of a high power density and high efficiency permanent magnet DC motor, Journal of Magnetism and Magnetic Materials, Volume 209, Number 1, February 2000, pp. 234-236(3)-Publisher: Elsevier.

[4] MI. Chunting CHRIS : Analytical design of permanent-magnet traction-drive motors" Magnetics, IEEE Transactions on Volume 42, Issue 7, July 2006 Page(s):1861 - 1866 Digital Object Dentifier 10.1109/TMAG.2006.874511.

[5] S.TOUNSI, R.NÉJI, F.SELLAMI : Conception d'un actionneur à aimants permanents pour véhicules électriques, Revue Internationale de Génie Électrique volume 9/6 2006 pp.693-718.

[6] Sid Ali. RANDI : Conception systématique de chaînes de traction synchrones pour véhicule électrique à large gamme de vitesse. Thèse de Doctorat 2003, Institut National Polytechnique de Toulouse, UMRCNRS Nº 5828.

[7] C. PERTUZA : Contribution à la définition de moteurs à aimants permanents pour un véhicule électrique routier. Thèse de docteur de 1'Institut National Polytechnique de Toulouse, Février 1996.

[8] S. TounsI, R. NEJI and F. SELLAmI: Mathematical model of the electric vehicle autonomy. ICEM2006 (16th International Conference on Electrical Machines), 2-5 September 2006 Chania-Greece, CD: PTM4-1.

[9] R. NEJI, S. TOUNSI, F. SELLAMI: Contribution to the definition of a permanent magnet motor with reduced production cost for the electrical vehicle propulsion. Journal European Transactions on Electrical Power (ETEP), Volume 16, issue 4, 2006, pp. 437-460.

[10] P. BASTIANI : Stratégies de commande minimisant les pertes d'un ensemble convertisseur machine alternative : application à la traction électrique. Thèse INSA 01 ISAL 0007, 2001.

[11] G. Henriot : Traité théorique et pratique des engrenages : théorie et technologie 1. tome 1 Edition Dunod 1952.
[12] D-H. Cho, J-K. Kim, H-K. Jung and C-G. Lee: Optimal design of permanent-magnet motor using autotuning Niching Genetic Algorithm, IEEE Transactions on Magnetics, Vol. 39, No. 3, May 2003.

[13] Islam, M. S., Islam, R., \& Sebastian, T. : Experimental verification of design techniques of permanent-magnet synchronous motors for low-torque-ripple applications. Industry Applications, IEEE Transactions on, vol 47 no 1, p. 88-95, 2011.

[14] Parasiliti, F., Villani, M., Lucidi, S., \& Rinaldi, F. : Finite-element-based multiobjective design optimization procedure of interior permanent magnet synchronous motors for wide constant-power region operation. Industrial Electronics, IEEE Transactions on, vol 59 no 6, p. 2503-2514, 2012.

[15] Mahmoudi, A., Kahourzade, S., Rahim, N. A., \& Ping, H. W. : Improvement to performance of solid-rotor-ringed line-start axial-flux permanent-magnet motor. Progress In Electromagnetics Research, 124, p. 383-404, 2012.

[16] Duan, Y., \& Ionel, D. M. : A review of recent developments in electrical machine design optimization methods with a permanent-magnet synchronous motor benchmark study. Industry Applications, IEEE Transactions on, vol 49 no 3, p. 1268-1275, 2013.

[17] Liu, G., Yang, J., Zhao, W., Ji, J., Chen, Q., \& Gong, W. : Design and analysis of a new fault-tolerant permanent-magnet vernier machine for electric vehicles. Magnetics, IEEE Transactions on, vol 48 no 11, p. 4176-4179, 2012.

[18] Lee, S., Kim, K., Cho, S., Jang, J., Lee, T., \& Hong, J. : Optimal design of interior permanent magnet synchronous motor considering the manufacturing tolerances using Taguchi robust design. Electric Power Applications, IET, vol 8 no 1, 23-28, 2014 .

[19] TOUNSI, R. NEJI and F. SELLAMI : Electric vehicle control maximizing the autonomy : 3rd International Conference on Systems, Signal \& Devices (SSD’05), SSD-PES 102, 21-24 March 2005, Sousse, Tunisia. 